\title{
INTERACTIVE TEACHING METHODS: CHALLENGES AND PERSPECTIVES
}

\author{
Madona Giorgdze ${ }^{1 *}$, Marine Dgebuadze ${ }^{2}$ \\ ${ }^{1}$ Dr., llia State University, GEORGIA, madona_giorgadze@iliauni.edu.ge \\ 2Dr., llia State University, GEORGIA, marine_dgebuadze@iliauni.edu.ge \\ ${ }^{*}$ Corresponding author
}

\begin{abstract}
Georgian educational system has gone through the traditional methods of teaching. One of the main forms of teaching in high school was a lecture, during which the lecturer was a transmitter and the student was a recipient of knowledge.

Integration with modern Euro-Atlantic educational space requires modernization of existing learning methods and the introduction of modern activities in the process of learning that will facilitate the establishment of an active, independent and free person with critical thinking. Western education system became the main focus of the Georgian educational policy.

The educational strategy has been changed and its main purpose has become bringing up of free, active, informed and responsible citizens, equipped with the skills of critical thinking and loyal to the modern democratic community in order to meet the demands of present-day democratic society.

The analysis of the research results shows that interactive teaching best helps students to get maximum involvement in the lecturing process. The student is not only a passive recipient of knowledge, who is constantly in the position of the listener but is actively involved in the lecturing process and gets maximum knowledge. As a result, the information received is remembered for a longer time.

Recent studies show that interactive learning helps the learner not only to easily acquire new material but to memorize it for a longer period of time.

The article does not attempt to contrast interactive and traditional methods but rather to highlight advantages of the interactive method and underline its effectiveness to activate creative thinking, analytic and argumentation skills in students.
\end{abstract}

Keywords: Interactive Teaching, traditional methods, teacher's role

\section{INTRODUCTION}

A teaching method is formed in the teaching process through the interaction between the teacher and learner. Within the existing learning conditions, the learning process is considered as an interaction between the teacher and student, aiming to transfer common knowledge, skills, and values to the student. 
From the very first day when the teaching situation emerged up today there have been formed only three widely spread forms of the interaction between a teacher and student:

\section{Passive methods;}

2. Active methods;

\section{Interactive methods.}

A passive method of instruction is a form of interaction between the teacher and students with the teacher being the center of the lesson while the learner remains to be a passive listener. Feedback on such lessons is conducted through surveys, independent tasks, tests and so on. The passive method is considered as the most inefficient method in terms of material use, but the advantages of this method include the ability to prepare less labor-intensive lessons in advance and present a large amount of information in a short time.

For many years the passive method of instruction had been the most popular and the single approach used in Georgian learning situation. This can be regarded as a defect of that educational period and can be explained by the logic of totalitarian system - the Soviet school did not aim at bringing up an active, critical and independent citizen. The role of the pupil in the Soviet school was extremely weakened and this attitude was obvious at different levels as well - the structure of lessons and the nature of the pedagogical methods used in the course of the lesson (an active teacher: a passive learner /a teacher presenting: a learner listening).

After the fall of the Soviet Union, significant changes were made to the Georgian educational system. Western education system became the main focus of the Georgian educational policy. The educational strategy has been changed and its main purpose became bringing up of free, active, informed and responsible citizens, equipped with the skills of critical thinking and loyal to the modern democratic community in order to meet the demands of present-day democratic society. For Georgia, with its short tradition of democracy, it has become important to increase citizens' democratic awareness and to actively engage them in the public life. For this purpose, reform and modernization of the education system have been initiated, which envisages facilitating the establishment of a genuine knowledge-based society.

\section{METHODS REVIEW}

An active approach is a form of a teacher-student interaction equally involving both a teacher and students. In this form of learning, students are not passive listeners anymore but they are active participants in the learning process. Because of these advantages, a lot of teachers choose this method of instruction. In some cases, this method is effective if employed by experienced teachers with the learners who have clearly defined learning objective. If passive lessons represent an authoritative style of instruction, the active approach is a democratic style (see Fig.1 and Fig 2) Active and interactive approaches have a lot in common. In general, an interactive method can be considered as a modern version of active methods. In contrast to the passive approach, active learning is focused on a closer relationship between learners and a teacher, and students are more active in the learning process (see Fig. 3). The main difference between active and interactive approach is that, in contrast to active approach, interactive learning involves students' interaction not only with the teacher but with each other as well.

An interactive approach involves interaction in dialogue mode ("inter" - reciprocally, "act" - do, perform). In other words, an interactive teaching method is a form of learning and communicative activity in which students are involved in the learning process and reflect on what they know and what they are thinking. Unlike a traditional teaching method oriented on the teacher whose main function is to assist learners and facilitate, interactive learning focuses on students 'needs, abilities, interests. While in a traditional approach teacher is a center of the learning process and learners are passive and only receive information, in a learner-oriented system the teacher and the learner swap their traditional roles enabling the learner to actively engage in the learning process and be the center of the classroom (Fig. 1.). Based on his knowledge and experience, learners categorize, analyze, assume opinions, acquire new skills, and develop their attitudes towards facts and events. 


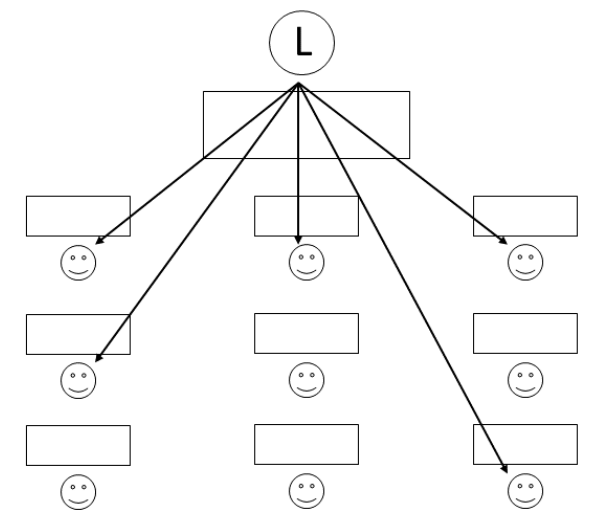

Fig. 1. Passive methods

The teacher's role in interactive learning is directed towards achieving the goals of students in the process of teaching. The teacher makes a lesson plan - interactive activities and assignments, through the working of which students acquire new information and an individual task is transformed into a group task. Each member of the group contributes to the whole group's success (Fig. 2.). Interactive exercises and tasks that students perform are the basic components of interactive lessons. The use of interactive teaching methods ensures full participation of students in the learning process, and which is a major source of learning. The fundamental difference between traditional and interactive activities is that the student does not only revise and strengthen his knowledge but also constructs and completes it with new material.

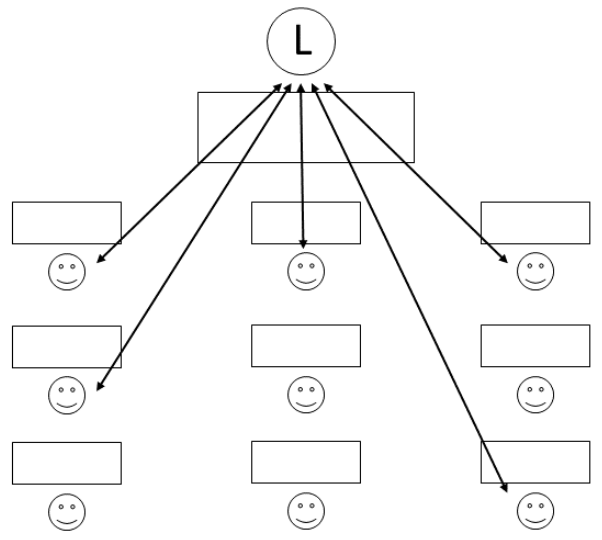

Fig. 2. Active methods

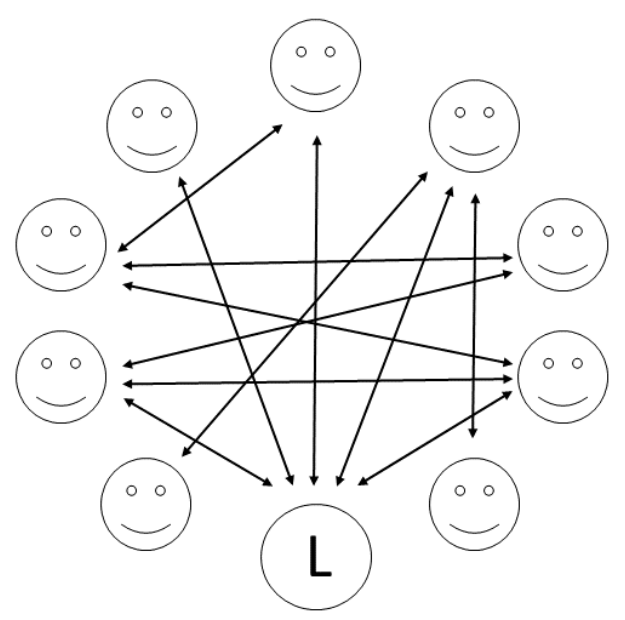




\section{Fig. 3. Interactive method}

Among widely spread and popular interactive approaches, we can single out the following:

1. Creative tasks;

2. Games (role-plays, imitations, business and development games);

3. Use of human resources (excursions, inviting experts);

4. Social Projects;

5. Use of new material (interactive lectures, video-audio materials, student in the role of a "teacher", Socratic dialogue, asking questions);

6. Solving tasks (associative maps, brain storming, case analysis).

Practice proves that using the above-mentioned interactive methods helps to achieve the results of modern education. They help learning process to be conducted in such a way that all students are equally involved in the cognitive process, each individual contributes to the teaching process, students exchange information and ideas. This relationship allows students not only to acquire knowledge but also develop communicative skills: the ability to listen to others, evaluate different points of view, participate in discussions, make joint decisions, develop tolerance, etc.

Recent studies show that interactive learning helps the learner not only to easily acquire new material but to memorize it for a longer period of time. The diagram below shows clearly that through passive learning, the learner can memorize only $30 \%$ of the material, while the interactive learning enables us to memorize $90 \%$ of the received information (Fig. 3.).

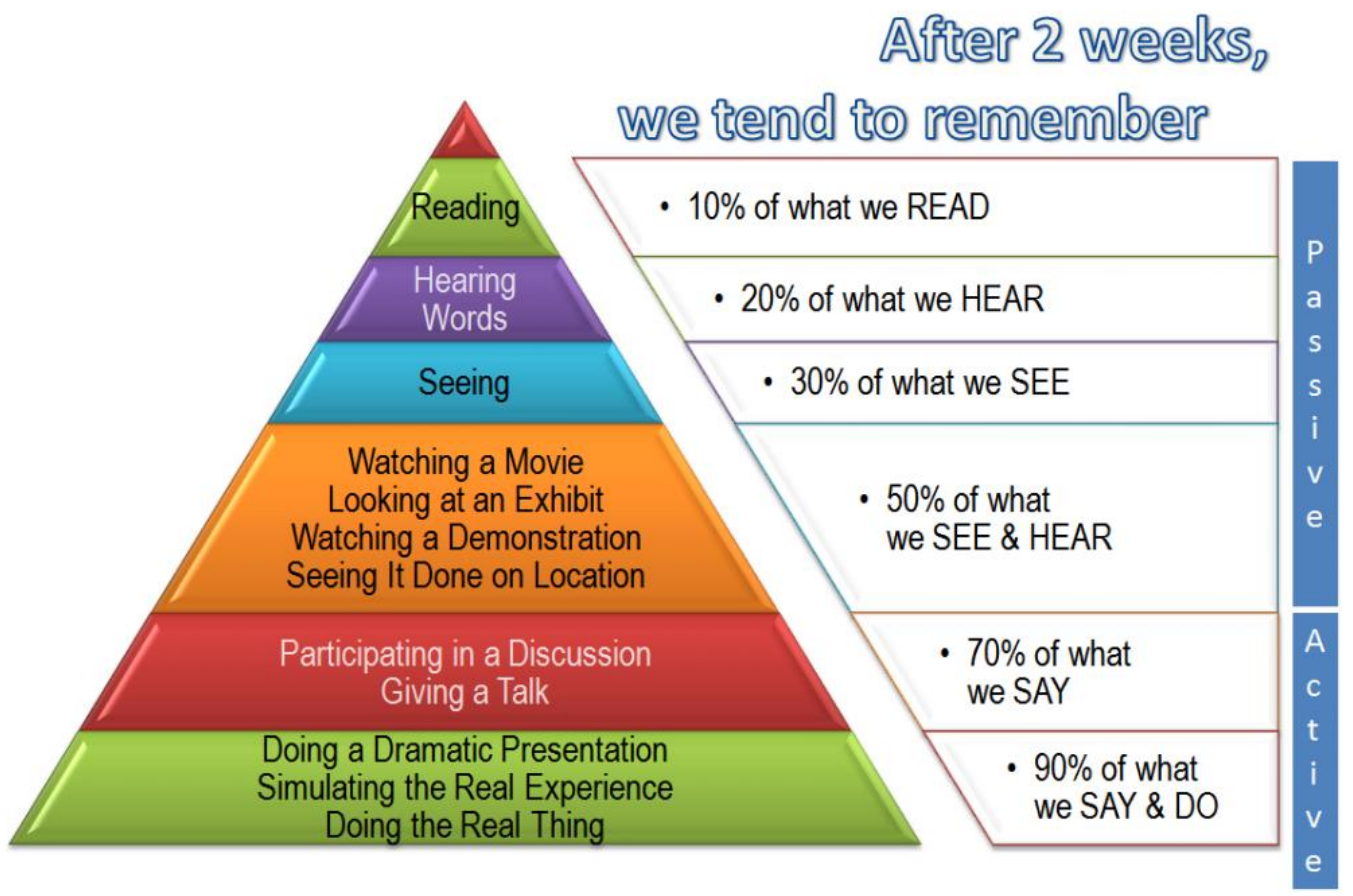

Fig. 4. Passive and active learning diagram (Edgar Dale's cone of experience http://teachernoella.weebly.com/dales-cone-of-experience.html)

\section{CONCLUSION}

As a conclusion we can say that the article does not attempt to contrast interactive and traditional methods but rather to highlight advantages of the interactive method and underline its effectiveness to activate creative thinking, analytic and argumentation skills in students; to develop conversation, discussion, teamworking and effective communication skills as emotional contacts created through interactive learning make students listen to peers. Interactive methods in multicultural education allow students to have not only knowledge and compassion for others but also be able to make rational decisions in any situation in order to develop the most acceptable models of thinking, action, and communication. 


\section{REFERENCE LIST}

Atanasescu, C., Dumitru, F. Interactive teaching-learning methods in the interdisciplinary approach of natural sciences from the mentor-teacher's perspective. Available at: https://www.upit.ro/ document/4820/paper 2.pdf (03.09.2017)

Dumitru, Ion Al. (2000) .Developing the critical thinking and efficient learning. Timișoara: West.Pp. 93-95

Edgar Dale's cone of experience http://teachernoella.weebly.com/dales-cone-of-experience.html Available at: (07.09.2017)

Interactive Teaching Styles Used in the Classroom. Available at:

http://education.cuportland.edu/blog/tech-ed/5-interactive-teaching-styles-2/ (07.09.2017)

Macarie, C. (2005). Modern methodological alternatives a challenge for the teaching activity. Târgu- Jiu :Măiastra. Pp. 22-25

Yakovleva, N., Yakovlev E. (2014). Interactive teaching methods in contemporary higher education. Pacific Science Review 16. www.sciencedirect.com. Pp. 75-80 